\title{
Adverse Event Occurrence Pattern Code
}

National Cancer Institute

\section{Source}

National Cancer Institute. Adverse Event Occurrence Pattern Code. NCI Thesaurus. Code C93715.

A coded value specifying the time recurrence by which an adverse event occurs. 